\title{
Peirce on Intuition, Instinct, \& Common Sense
}

\section{Kenneth Boyd and Diana Heney}

\section{OpenEdition}

\section{Journals}

Electronic version

URL: http://journals.openedition.org/ejpap/1035

DOI: 10.4000/ejpap.1035

ISSN: 2036-4091

\section{Publisher}

Associazione Pragma

\section{Electronic reference}

Kenneth Boyd and Diana Heney, « Peirce on Intuition, Instinct, \& Common Sense », European Journal of Pragmatism and American Philosophy [Online], IX-2 | 2017, Online since 22 January 2018, connection on 19 April 2019. URL : http://journals.openedition.org/ejpap/1035; DOI : 10.4000/ejpap.1035

This text was automatically generated on 19 April 2019

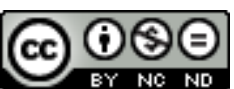

Author retains copyright and grants the European Journal of Pragmatism and American Philosophy right of first publication with the work simultaneously licensed under a Creative Commons AttributionNonCommercial-NoDerivatives 4.0 International License. 


\title{
Peirce on Intuition, Instinct, \& Common Sense
}

\author{
Kenneth Boyd and Diana Heney
}

\section{AUTHOR'S NOTE}

We thank our audience at the 2017 Canadian Philosophical Association meeting at Ryerson University for a stimulating discussion of the main topics of this paper. Thanks also to our wonderful co-panelists on that occasion, who gathered with us to discuss prospects for pragmatism in the 21st century: Shannon Dea, Pierre-Luc Dostie Proulx, and Andrew Howat.

1 In addition to being a founder of American pragmatism, Charles Sanders Peirce was a scientist and an empiricist. Peirce's methodological commitments are as readily on display in his philosophical endeavours as in his geodetic surveys. In both, and over the full course of his intellectual life, Peirce exhibits what he terms the laboratory attitude: "my attitude was always that of a dweller in a laboratory, eager to learn what I did not yet know, and not that of philosophers bred in theological seminaries, whose ruling impulse is to teach what they hold to be infallibly true" (CP 1.4). Alongside a scientific mindset and a commitment to the method of inquiry, where does common sense fit in? That Peirce is with the person contented with common sense "in the main" suggests that there is a place for common sense, systematized, in his account of inquiry - but not at the cost of critical examination.

2 Peirce does at times directly address common sense; however, those explicit engagements are relatively infrequent. In this paper, we argue that getting a firm grip on the role of common sense in Peirce's philosophy requires a three-pronged investigation, targeting his treatment of common sense alongside his more numerous remarks on intuition and instinct. By excavating and developing Peirce's concepts of instinct and intuition, we show that his respect for common sense coheres with his insistence on the methodological superiority of inquiry. We conclude that Peirce shows us the way to a distinctive 
epistemic position balancing fallibilism and anti-scepticism, a pragmatist common sense position of considerable interest for contemporary epistemology given current interest in the relation of intuition and reason.

\section{Common Sense, Take 1: A Tension}

3 Peirce's discussions of common sense are often accompanied by a comparison to the views of the "Scotch philosophers," among whom Peirce predominantly includes Thomas Reid. ${ }^{1}$ This is not surprising: Reid was a significant influence on Peirce, and for Reid common sense played an important role in his epistemology and view of inquiry. Peirce takes his "critical common-sensism" to be a variant on the "common-sensism" that he ascribes to Reid, so much so that Peirce often feels the need to be explicit about how his view is different. Here, then, we want to start by looking briefly at Reid's conception of common sense, and what Peirce took the main differences to be between it and his own views. As we will see, what makes Peirce's view unique will also be the source of a number of tensions in his view.

4 For Reid, "common sense" is polysemous, insofar as it can apply both to the content of a particular judgment (what he will sometimes refer to as a "first principle") and to a faculty that he takes human beings to have that produces such judgments. Common sense judgments are not "common" in the sense in which most people have them, but are common insofar as they are the product of a faculty which everyone possesses. A significant aspect of Reid's notion of common sense is the role he ascribes to it as a ground for inquiry. As John Greco (2011) argues, common sense for Reid has both an epistemic and methodological priority in inquiry: judgments delivered by common sense are epistemically prior insofar as they are known non-inferentially, and methodologically prior, given that they are first principles that act as a foundation for inquiry. With respect to the former, Reid says of beliefs delivered by common sense that " $[t]$ here is no searching for evidence, no weighing of arguments; the proposition is not deduced or inferred from another; it has the light of truth in itself, and has no occasion to borrow it from another" (Essays VI, IV: 434); with respect to the latter, Reid argues that "all knowledge got by reasoning must be built upon first principles. This is as certain as that every house must have a foundation." (Essays VI, IV: 435). Since reasoning must start somewhere, according to Reid, there must be some first principles, ones which are not themselves the product of reasoning. Furthermore, since these principles enjoy an epistemic priority, we can be assured that our inquiry has a solid foundation, and thus avoid the concerns of the skeptic.

5 In these broad terms we can see why Peirce would be attracted to a view like Reid's. Peirce is, of course, adamant that inquiry must start from somewhere, and from a place that we have to accept as true, on the basis of beliefs that we do not doubt. So one might think that Peirce, too, is committed to some class of cognitions that possesses methodological and epistemic priority. But as we will shall see, despite surface similarities, their views are significantly different. Notably, Peirce does not grant common sense either epistemic or methodological priority, at least in Reid's sense.

6 Peirce spends much of his 1905 "Issues of Pragmaticism" distinguishing his critical common-sensism from the view that he attributes to Reid. Here, Peirce agrees with Reid that inquiry must have as a starting point some indubitable propositions. He disagrees with Reid, however, about what these starting points are like: Reid considers them to be 
fixed and determinate (Peirce says that although the Scotch philosophers never wrote down all the "original beliefs," they nevertheless thought "it a feasible thing, and that the list would hold good for the minds of all men from Adam down" (CP5.444)), but for Peirce such propositions are liable to change over time (EP2: 349). That common sense is malleable in this way is at least partly the result of the fact that common sense judgments for Peirce are inherently vague and aspire to generality: we might have a common sense judgment that, for example, 'Man is mortal,' but since it is indeterminate what the predicate 'mortal' means, the content of the judgment is thus vague, and thus liable to change depending on how we think about mortality as we seek the broadest possible application of the judgment.

7 Peirce takes the second major point of departure between his view and that of the Scotch philosophers to be the role of doubt in inquiry and, in turn, the way in which common sense judgments have epistemic priority. For Peirce, common sense judgments, like any other kind of judgment, have to be able to withstand scrutiny without being liable to genuine doubt in order to be believed and in order to play a supporting role in inquiry. For Reid, however, first principles delivered by common sense have positive epistemic status even without them having withstood the scrutiny of doubt. This is not to say that they have such a status simply because they have not been doubted. As Peirce notes, this kind of "innocent until proven guilty" interpretation of Reid's common sense judgments is mistaken, as it conflates two senses of "because" in the common-sensist's statement that common sense judgments are believed because they have not been criticized: one sense in which a judgment not having been criticized is a reason to believe it, and another sense in which it is believed simply because one finds oneself believing it and has not bothered to criticize it. Peirce states that neither he nor the common-sensist accept the former, but that they both accept the latter (CP 5.523). Nevertheless, common sense judgments for Reid do still have epistemic priority, although in a different way. As Greco puts it, "Reid's account of justification in general is that it arises from the proper functioning of our natural, non-fallacious cognitive faculties" (149), and since common sense for Reid is one such faculty, our common sense judgments are thus justified without having to withstand critical attention.

8 This is a significant point of departure for Peirce from Reid. As we will see in what follows, that Peirce is ambivalent about the epistemic status of common sense judgments is reflective of his view that there is no way for a judgment to acquire positive epistemic status without passing through the tribunal of doubt. Furthermore, we will see that Peirce does not ascribe the same kind of methodological priority to common sense that Reid does, as Peirce does not think that there is any such thing as a "first cognition" (something that Reid thinks is necessary in order to stop a potential infinite regress of cognitions).

9 Although we have seen that in contrasting his views with the common-sense Scotch philosophers Peirce says a lot of things about what is view of common sense is not, he does not say a lot about what common sense is. In fact, to the extent that Peirce's writings grapple with the challenge of constructing his own account of common sense, they do so only in a piecemeal way. To make matters worse, the places where he does remark on common sense directly can offer a confusing picture. That common sense for Peirce lacks the kind stability and epistemic and methodological priority ascribed to it by Reid means that it will be difficult to determine when common sense can be trusted. ${ }^{2}$ 
10 This brings us back our opening quotation, which clearly contains the tension between common sense and critical examination. Peirce is with the person who is contented with common sense - at least, "in the main." This makes sense; after all, he has elsewhere described speculative metaphysics as "puny, rickety, and scrofulous" (CP 6.6), and common sense as part of what's needed to navigate our "workaday" world, where it "usually hits the nail on the head" (CP 1.647; W3 10-11). But in the same quotation, Peirce also affirms fallibilism with respect to both the operation and output of common sense: some of those beliefs and habits which get lumped under the umbrella of "common sense" are "merely obiter dictum." The so-called 'first principles' of both metaphysics and common sense are open to, and must sometimes positively require, critical examination. Peirce's scare quotes here seem quite intentional, for the principles taken as bedrock for practical purposes may, under scrutiny, reveal themselves to be the bogwalker's ground - a position that is "only provisional," where one must "find confirmations or else shift its footing. [...] It still is not standing upon the bedrock of fact. It is walking upon a bog, and can only say, this ground seems to hold for the present. Here I will stay till it begins to give way." (CP 5.589). We can conclude that, epistemically speaking, an appeal to common sense does not mean that we get decision principles for nothing and infallible beliefs for free. Nonetheless, common sense has some role to play.

11 Further examples add to the difficulty of pinning down his considered position on the role and nature of common sense. In one of Peirce's best-known papers, "Fixation of Belief," common sense is portrayed as deeply illogical:

We can see that a thing is blue or green, but the quality of being blue and the quality of being green are not things which we see; they are products of logical reflection. The truth is, that common-sense, or thought as it first emerges above the level of the narrowly practical, is deeply imbued with that bad logical quality to which the epithet metaphysical is commonly applied; and nothing can clear it up but a severe course of logic. (EP 1.113)

The charge here is that methodologically speaking, common sense is confused. Given the context - an argument in favour of inquiry by way of critique against other methods - we might dismiss this as part of a larger insistence that belief fixation should (in order to satisfy its own function and in a normative sense of 'should') be logical, rather than driven by fads, preferences, or temporary exigencies.

Nor is "Fixation" the only place where Peirce refers derisively to common sense. A similar kind of charge is made in the third of Peirce's 1903 Harvard lectures:

Suppose two witnesses A and B to have been examined, but by the law of evidence almost their whole testimony has been struck out except only this: A testifies that B's testimony is true. B testifies that A's testimony is false. Common sense would certainly declare that nothing whatever was testified to. But I cannot admit that judgments of common sense should have the slightest weight in scientific logic, whose duty it is to criticize common sense and correct it. (PPM 175)

While the 1898 Cambridge lectures are one of the most contentious texts in Peirce's body of written work, the Harvard lectures do not have such a troubled interpretive history. We stand with other scholars who hold that Peirce is serious about much of what he says in the 1898 lectures (despite their often ornery tone), ${ }^{3}$ but there is no similar obstacle to taking the Harvard lectures seriously. ${ }^{4}$ So we must consider how common sense could be both unchosen and above reproach, but also open to and in need of correction.

How can these criticisms of common sense be reconciled with Peirce's remark there is no "direct profit in going behind common sense" - no point, we might say, in seeking to 
undermine it? It is clear that there is a tension here between the presentation of common sense as "those ideas and beliefs that man's situation absolutely forces upon him" and common sense as a way of thinking "deeply imbued with [...] bad logical quality," standing in need of criticism and correction. How can what is forced upon one even be open to correction? Must we accept that some beliefs and ideas are forced, and that this places them beyond the purview of logic? Such a move would seem to bring Peirce much closer to James than he preferred to see himself. ${ }^{5}$ It would also seem to cut against what Peirce himself regarded as the highest good of human life, the growth of "concrete reasonableness" (CP 5.433; 8.138), which might fairly be regarded as unifying logical integrity with everyday reasoning - reasonableness, made concrete, could thereby be made common, as it would be instantiated in real and in regular patterns of reasoning.

Despite this tension, we are cautiously optimistic that there is something here in Peirce's thought concerning common sense which is important for the would-be Peircean; furthermore, by untangling the knots in Peirce's portrayal of common sense we can apply his view to a related debate in contemporary metaphilosophy, namely that concerning whether we ought to rely on what we find intuitive when doing philosophy. In order to help untangle these knots we need to turn to a number of related concepts, ones that Peirce is not typically careful in distinguishing from one another: intuition, instinct, and il lume naturale. We argue that all of these concepts are importantly connected to common sense for Peirce. We start with Peirce's view of intuition, which presents an interpretive puzzle of its own.

\section{A Neighboring Puzzle: Common Sense Without Intuition}

17 A 21st century reader might well expect something like the following line of reasoning: Peirce is a pragmatist; pragmatists care about how things happen in real social contexts; in such contexts people have shared funds of experience, which prime certain intuitions (and even make them fitting or beneficial); so: Peirce will offer an account of the place of intuition in guiding our situated epistemic practices. That reader will be disappointed. Instead, we find Peirce making the surprising claim that there are no intuitions at all.

This claim appears in Peirce's earliest (and perhaps his most significant) discussion of intuition, in the 1868 "Questions Concerning Certain Faculties Claimed For Man." Here, Peirce challenges the Cartesian foundationalist view that there exists a class of our cognitions whose existence do not depend on any other cognitions, which can be known immediately, and are indubitable. A member of this class of cognitions are what Peirce calls an intuition, or a "cognition not determined by a previous cognition of the same object, and therefore so determined by something out of the consciousness" (CP 5.213; EP1: 11, 1868). Peirce's main goal throughout the work, then, is to argue that, at least in the sense in which he presents it here, we do not have any intuitions.

To get to this conclusion we need to first make a distinction between two different questions: whether we have intuitions, and whether we have the faculty of intuition. These two questions go together: first, to have intuitions we would need to have a faculty of intuition, and if we had no reason to think that we had such a faculty we would then similarly lack any reason to think that we had intuitions; second, in order to have any reason to think that we have such a faculty we would need to have reason to think that 
we have such intuitions. Peirce thus attacks the existence of intuitions from two sides: first by asking whether we have a faculty of intuition, and second by asking whether we have intuitions at all. His answer to both questions is negative.

In arguing against a faculty of intuition, Peirce notes that, while we certainly feel as though some of our beliefs and judgments are ones that are the result of an intuitive faculty, we are generally not very good at determining where our cognitions come from. For instance, inferences that we made in the past but for which we have forgotten our reasoning are ones that we may erroneously identify as the result of intuition. Peirce here provides examples of an eye-witness who thinks that they saw something with their own eyes but instead inferred it, and a child who thinks that they have always known how to speak their mother tongue, forgetting all the work it took to learn it in the first place. Indeed, Peirce notes that many things that we used to think we knew immediately by intuition we now know are actually the result of a kind of inference: some examples he provides are our inferring a three-dimensional world from the two-dimensional pictures that are projected on our retinas (CP 5.219), that we infer things about the world that are occluded from view by our visual blind spots (CP 5.220), and that the tones that we can distinguish depend on our comparing them to other tones that we hear (CP 5.222).

That the presence of our cognitions can be explained as the result of inferences we either forgot about or did not realize we made thus undercuts the need to posit the existence of a distinct faculty of intuition. Where intuition seems to play the largest role in our mental lives, Peirce claims, is in what seems to be our ability to intuitively distinguish different types of cognitions - for example, the difference between imagination and real experience - and in our ability to know things about ourselves immediately and noninferentially. But in both cases, Peirce argues that we can explain the presence of our cognitions again by inference as opposed to intuition. Consider what appears to be our ability to intuit that one of our cognitions is the result of our imagination and another the result of our experience: surely we are able to tell fantasy from reality, and the way in which we do this at least seems to be immediately and non-inferentially. Not so, says Peirce: that we can tell the difference between fantasy and reality is the result not of intuition, but an inference on the basis of the character of those cognitions. In effect, cognitions produced by fantasy and cognitions produced by reality feel different, and so on the basis of those feelings we infer their source.

Denying the claim that we have an intuitive source of self-knowledge commits Peirce to something more radical, namely that we lack any power of introspection, as long as introspection is conceived of as a way of coming to have beliefs about ourselves and our mental lives directly and non-inferentially. Instead, all of our knowledge of our mental lives is again the product of inference, on the basis of "external facts" (CP 5.244). That we can account for our self-knowledge through inference as opposed to introspection again removes the need to posit the existence of any kind of intuitive faculty.

Thus, Peirce's argument is that if we can account for all of the cognitions that we previously thought we possessed as a result of intuition by appealing to inference then we lack reason to believe that we do possess such a faculty. There is, however, a more theoretical reason why we might think that we need to have intuitions. The reason is the same reason why Reid attributed methodological priority to common sense judgments: if all cognitions are determined by previous cognitions, then surely there must, at some point in the chain of determinations, be a first cognition, one that was not determined by anything before it, lest we admit of an infinite regress of cognitions. This regress appears 
vicious: if all cognitions require an infinite chain of previous cognitions, then it is hard to see how we could come to have any cognitions in the first place. Hence, we must have some intuitions, even if we cannot tell which cognitions are intuitions and which ones are not.

Peirce does not purport to solve this problem definitively; rather, he argues that the apparent regress is not a vicious one. He compares the problem to Zeno's paradox namely the problem of accounting for how Achilles can overtake a tortoise in a race, given that Achilles has to cover an infinite number of intervals in order to do so: that we do not have a definitive solution to this problem does not mean that Achilles cannot best a tortoise in a footrace. Similarly, although a cognition might require a chain of an infinite number of cognitions before it, that does not mean that we cannot have cognitions at all. If we accept that the necessity of an infinity of prior cognitions does not constitute a vicious regress, then there is no logical necessity in having a first cognition in order to explain the existence of cognitions. One of the consequences of this view, which Peirce spells out in his "Some Consequences of Four Incapacities," is that "we have no power of intuition, but every cognition is determined logically by previous cognitions" (CP 5.265). Thus, cognitions arise not from singular previous cognitions, but by a "process of cognition" (CP 5.267). Here, then, we see again how Peirce's view differs from Reid's: there are no individual judgments that have methodological priority, because there is no need for a regress-stopper for cognitions.

Peirce, then, is unambiguous in denying the existence of intuitions at the end of the 1860s. So it is rather surprising that Peirce continues to discuss intuitions over the course of his writings, and not merely to remind us that they do not exist. Unsurprisingly, given other changes in the way Peirce's system is articulated, his engagement with the possibility of intuition takes a different tone after the turn of the century. During this late stage, Peirce sometimes appears to defend the legitimacy of intuition, as in his 1902 "The Minute Logic":

I strongly suspect that you hold reasoning to be superior to intuition or instinctive uncritical processes of settling your opinions. What basis of fact is there for this opinion? (CP 2.129)

At other times, he seems ambivalent about them, as can be seen in his 1910 "Definition":

One of the old Scotch psychologists, whether it was Dugald Stewart or Reid or which other matters naught, mentions, as strikingly exhibiting the disparateness of different senses, that a certain man blind from birth asked of a person of normal vision whether the color scarlet was not something like the blare of a trumpet; and the philosopher evidently expects his readers to laugh with him over the incongruity of the notion. But what he really illustrates much more strikingly is the dullness of apprehension of those who, like himself, had only the conventional education of the eighteenth century and remained wholly uncultivated in comparing ideas that in their matter are very unlike. For everybody who has acquired the degree of susceptibility which is requisite in the more delicate branches of reasoning - those kinds of reasoning which our Scotch psychologist would have labelled "Intuitions" with a strong suspicion that they were delusions will recognize at once so decided a likeness between a luminous and extremely chromatic scarlet, like that of the iodide of mercury as commonly sold under the name of scarlet [and the blare of a trumpet] that I would almost hazard a guess that the form of the chemical oscillations set up by this color in the observer will be found to resemble that of the acoustical waves of the trumpet's blare. (CP 1.312) 
What explains Peirce's varying attitudes on the nature of intuition, given that he decisively rejects the existence of intuitions in his early work? The answer, we think, can be found in the different ways that Peirce discusses intuition after the 1860s. In the above passage from "The Minute Logic," for instance, Peirce portrays intuition as a kind of "uncritical process" of settling opinions, one that is related to instinct. This also seems to be the sense under consideration in the 1910 passage, wherein intuitions might be misconstrued as delusions. It is no surprise, then, that Peirce would not consider an uncritical method of settling opinions suitable for deriving truths in mathematics. It is surprising, though, what Peirce says in his 1887 "A Guess at the Riddle":

Intuition is the regarding of the abstract in a concrete form, by the realistic hypostatisation of relations; that is the one sole method of valuable thought. Very shallow is the prevalent notion that this is something to be avoided. You might as well say at once that reasoning is to be avoided because it has led to so much error; quite in the same philistine line of thought would that be and so well in accord with the spirit of nominalism that I wonder some one does not put it forward. The true precept is not to abstain from hypostatisation, but to do it intelligently. (CP 1.383; EP1: 262)

Far from being untrusting of intuition, Peirce here puts it on the same level as reasoning, at least when it comes to being able to lead us to the truth. How can we reconcile the claims made in this passage with those Peirce makes elsewhere?

Here is our proposal: taking seriously the nominal definition that Peirce later gives of

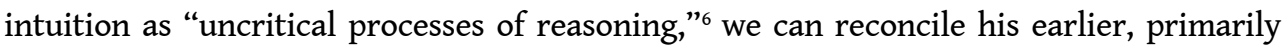
negative claims with the later, more nuanced treatment by isolating different ways in which "intuition" appears to be functioning in the passages that stand in tension with one another. The solution to the interpretive puzzle turns on a disambiguation between three related notions: intuition (in the sense of "first cognition"); instinct (which is often implicated in "intuitive" reasoning); and il lume naturale. Once we disentangle these senses, we will be able to see that ways in which instinct and il lume naturale can fit into the process of inquiry - respectively, by promoting the growth of concrete reasonableness and the maintenance of the epistemic attitude proper to inquiry.

\section{“First Cognition"}

The first thing to notice is that what Peirce is responding to in 1868 is explicitly a Cartesian account of how knowledge is acquired, and that the piece of the Cartesian puzzle singled out as "intuition" - and upon which scorn is thereafter heaped - is not intuition in the sense of uncritical processes of reasoning. Intuition as "first cognition" read through a Cartesian lens is more likely to be akin to clear and distinct apprehension of innate ideas. Given Peirce's thoroughgoing empiricism, it is unsurprising that we should find him critical of intuition in that sense, which is not properly intuition at all. But the complaint is not simply that the Cartesian picture is insufficiently empiricist which would be, after all, mere question-begging. Classical empiricists, such as John Locke, attempt to shift the burden of proof by arguing that there is no reason to posit innate ideas as part of the story of knowledge acquisition: "He that attentively considers the state of a child, at his first coming into the world, will have little reason to think him stored with plenty of ideas, that are to be the matter of his future knowledge: It is by degrees he comes to be furnished with them" (np.106). Locke goes on to argue that the 
ideas which appear to us as clear and distinct become so through our sustained attention (np.107).

Peirce takes a different angle. Of the doctrine of innate ideas, he remarks that

The really unobjectionable word is innate; for that may be innate which is very abstruse, and which we can only find out with extreme difficulty. All those Cartesians who advocated innate ideas took this ground; and only Locke failed to see that learning something from experience, and having been fully aware of it since birth, did not exhaust all possibilities. (CP 4.92) innate instincts playing a role in inquiry. What Descartes has critically missed out on in focusing on the doctrine of clear and distinct perception associated with innate ideas is the need for the pragmatic dimension of understanding. Peirce argues in "How to Make Our Ideas Clear" that to understand a concept fully is not just to be able to grasp its instances and give it an analytic definition (what the dimensions of clarity and distinctness track), but also to be able to articulate the consequences of its appropriate use. "We must look to the upshot of our concepts in order rightly to apprehend them" (CP 5.3) - so, we cannot rightly apprehend a thing by a mode of cognition that operates quite apart from the use of concepts, which is what Peirce takes first cognition to be. On that understanding of what intuitions could be, we have no intuitions.

On Peirce's view, Descartes' mistake is not to think that there is some innate element operative in reasoning, but to think that innate ideas could be known with certainty through purely mental perception. As he puts it:

It would be all very well to prefer an immediate instinctive judgment if there were such a thing; but there is no such instinct. What is taken for such is nothing but confused thought precisely along the line of the scientific analysis. It would be a somewhat extreme position to prefer confused to distinct thought, especially when one has only to listen to what the latter has to urge to find the former ready to withdraw its contention in the mildest acquiescence. (CP 2.174)

Cognition of this kind is not to be had. But while rejecting the existence of intuition qua first cognition, Peirce will still use "intuition" to pick out that uncritical mode of reasoning. Next we will see that this use of "intuition" is closely related to another concept that Peirce employs frequently throughout his writings, namely instinct.

\section{Instinct}

At first pass, examining Peirce's views on instinct does not seem particularly helpful in making sense of his view of common sense, since his references to 'instinct' are also heterogeneous. But it is not altogether surprising that more than one thing is present under the umbrella of 'instinct,' nor is it so difficult to rule out the senses of 'instinct' that are not relevant to common sense. More interesting are the cases of instinct that are very sophisticated, such as cuckoo birds hiding their eggs in the nests of other birds, and the eusocial behaviour of bees and ants (CP 2.176).

Peirce's commitment to evolutionary theory shines through in his articulation of the relation of reason and instinct in "Reasoning and the Logic of Things," where he recommends that "we should chiefly depend not upon that department of the soul which is most superficial and fallible, - I mean our reason, - but upon that department that is deep and sure, - which is instinct" (RLT 121). Instinct is more basic than reason, in the 
sense of more deeply embedded in our nature, as our sharing it with other living sentient creatures suggests. Reason, having arisen later and less commonly, has not had the long trial that instinct has successfully endured. This is why when the going gets tough, Peirce believes that instinct should take over: "reason, for all the frills it customarily wears, in vital crises, comes down upon its marrow-bones to beg the succor of instinct" (RLT 111). Instinct is basic, but that does not mean that all instincts are "base," or on the order of animal urges. In fact, Peirce is clear in stating that he believes the word "instinct" can refer equally well to an inborn disposition expressed as a habit or an acquired habit. As he puts it, "since it is difficult to make sure whether a habit is inherited or is due to infantile training and tradition, I shall ask leave to employ the word 'instinct' to cover both cases" (CP 2.170). Peirce is not being vague about there being two such cases here, but rather noting the epistemic difficulty: there are sentiments that we have always had and always habitually expressed, so far as we can tell, but whether they are rooted in instinct or in training is difficult to discern. ${ }^{7}$

Despite their origins being difficult to ascertain, Peirce sets out criteria for instinct as conscious. To his definition of instinct as inherited or developed habit, he adds that instincts are conscious, determined in some way toward an end (what he refers to a quasipurpose), and capable of being refined by training. This set of features helps us to see how it is that reason can refine common sense qua instinctual response, and how common sense - insofar as it is rooted in instinct - can be capable of refinement at all. Such refinement takes the form of being "controlled by the deliberate exercise of imagination and reflection" (CP 7.381). Habits, being open to calibration and correction, can be refined. It is because instincts are habitual in nature that they are amenable to the intervention of reason.

Along with discussing sophisticated cases of instinct and its general features, Peirce also undertakes a classification of the instincts. Richard Atkins has carefully traced the development of this classification, which unfolds alongside Peirce's continual work on the classification of the sciences - a project which did not reach its mature form until after the turn of the century. According to Atkins, Peirce may have explicitly undertaken the classification of the instincts to help to classify practical sciences (Atkins 2016: 55). This makes sense; the practical sciences target conduct in a variety of arenas, where being governed by an appropriate instinct may be requisite to performing well. Peirce's classificatory scheme is triadic, presenting the categories of suicultual, civicultural, and specicultural instincts. The suicultual are those focused on the preservation and flourishing of one's self, while the civicultural support the preservation and flourishing of one's family or kin group.

For our investigation, the most important are the specicultural instincts, which concern the preservation and flourishing not of individuals or groups, but of ideas. Of these, the most interesting in the context of common sense are the grouping, graphic, and gnostic instincts. ${ }^{8}$ The grouping instinct is an instinct for association, for bringing things or ideas together in salient groupings (R1343; Atkins 2016: 62). Given Peirce's interest in generals, this instinct must be operative in inquiry to the extent that truth-seeking is seeking the most generalizable indefeasible claims. It is also clear that its exercise can at least sometimes involve conscious activity, as it is the interpretive element present in all experience that pushes us past the "thisness" of an object and its experiential immediacy, toward judgment and information of use to our community. 

up" (R 1343; Atkins 2016: 62). This connects with a tantalizing remark made elsewhere in Peirce's more general classification of the sciences, where he claims that some ideas are so important that they take on a life of their own and move through generations - ideas such as "truth" and "right." Such ideas, when woken up, have what Peirce called "generative life" (CP 1.219). When we consider the frequently realist character of socalled folk philosophical theories, we do see that standards of truth and right are often understood as constitutive.

The gnostic instinct is perhaps most directly implicated in the conversation about reason and common sense. In one place, Peirce presents it simply as "curiosity" (CP 7.58). In Atkins' words, the gnostic instinct "is an instinct to look beyond ideas to their upshot and purpose, which is the truth" (Atkins 2016: 62). That way of putting it demonstrates the gap between the idea of first cognition and what Peirce believes is necessary for truly understanding a concept - it is the gnostic instinct that moves us toward the pragmatic dimension.

All three of these instincts Peirce regards as conscious, purposive, and trainable, and all three might be thought of as guiding or supporting the instinctual use of our intelligence. But they are not the full story. Although instinct clearly has a place in the life of reason, it also has a limit. As he remarks in the incomplete "Minute Logic":

[...] [F]ortunately (I say it advisedly) man is not so happy as to be provided with a full stock of instincts to meet all occasions, and so is forced upon the adventurous business of reasoning, where the many meet shipwreck and the few find, not oldfashioned happiness, but its splendid substitute, success. When one's purpose lies in the line of novelty, invention, generalization, theory - in a word, improvement of the situation - by the side of which happiness appears a shabby old dud - instinct and the rule of thumb manifestly cease to be applicable. The best plan, then, on the whole, is to base our conduct as much as possible on Instinct, but when we do reason to reason with severely scientific logic. (CP 2.178)

Novelty, invention, generalization, theory - all gathered together as ways of improving the situation - require the successful adventure of reasoning well. As such, our attempts to improve our conduct and our situations will move through cycles of instinctual response and adventure in reasoning, with the latter helping to refine and calibrate the former.

In addition to there being situations where instinct simply runs out - Cornelius de Waal suggests that there are cases where instinct has produced governing sentiments that we now find odious, cases where our instinctual natures can produce conflicting intuitions or totally inadequate intuitions ${ }^{9}$ - instinct in at least some sense must be left at the laboratory door. For better or worse, ${ }^{10}$ Peirce maintains a distinction between theory and practice such that what he is willing to say of instinct in the practice of practical sciences is not echoed in his discussion of the theoretical:

I would not allow to sentiment or instinct any weight whatsoever in theoretical matters, not the slightest. Right sentiment does not demand any such weight; and right reason would emphatically repudiate the claim if it were made. True, we are driven oftentimes in science to try the suggestions of instinct; but we only try them, we compare them with experience, we hold ourselves ready to throw them overboard at a moment's notice from experience. If I allow the supremacy of sentiment in human affairs, I do so at the dictation of reason itself; and equally at the dictation of sentiment, in theoretical matters I refuse to allow sentiment any weight whatever. (CP 1. 634)

European Journal of Pragmatism and American Philosophy, IX-2 | 2017 
Instinct, or sentiment rooted in instinct, can serve as the supreme guide in everyday human affairs and on some scientific occasions as the groundswell of hypotheses. Right sentiment seeks no other role, and does not overstep its boundaries.

But there is a more robust sense of 'instinct' that goes beyond what happens around theoretical matters or at their points of origin, and can infiltrate inquiry itself - which is allowed in the laboratory door. That sense is what Peirce calls il lume naturale.

\section{Lume Naturale}

While Peirce's views about the appropriateness of relying on intuition and instinct in inquiry will vary, there is another related concept - il lume naturale - which Peirce consistently presents as appropriate to rely on. Peirce makes reference to il lume naturale throughout all periods of his writing, although somewhat sparsely. This is perhaps surprising, first, because talking about reasoning by appealing to one's "natural light" certainly sounds like an appeal kind of intuition or instinct, so that it is strange that Peirce should consistently hold it in high regard; and second, because performing inquiry by appealing to il lume naturale sounds similar to a method of fixing beliefs that Peirce is adamantly against, namely the method of the a priori. Indeed, the catalyst for his arguments in "The Fixation of Belief" stems from an apparent disillusionment with what Peirce saw as a dominant method of reasoning from early scientists, namely the appeal to an "interior illumination": he describes Roger Bacon's reasoning derisively, for example, when he says that Bacon thought that the best kind of experience was that which "teaches many things about Nature which the external senses could never discover, such as the transubstantiation of bread" (EP1: 110). Peirce argues that later scientists have improved their methods by turning to the world for confirmation of their experience, but he is explicit that reasoning solely by the light of one's own interior is a poor substitute for the illumination of experience from the world, the former being dictated by intellectual fads and personal taste.

To figure out what's going on here we need to look in more detail at what, exactly, Peirce thought "il lume naturale" referred to, and how it differed from other similar concepts like instinct and intuition. The best way to make sense of Peirce's view of il lume naturale, we argue, is as a particular kind of instinct, one that is connected to the world in an important way.

Passages that contain discussions of il lume naturale will, almost invariably, make reference to Galileo. ${ }^{11}$ In Peirce's 1891 "The Architecture of Theories," for example, he praises Galileo's development of dynamics while at the same time noting that,

A modern physicist on examining Galileo's works is surprised to find how little experiment had to do with the establishment of the foundations of mechanics. His principal appeal is to common sense and il lume naturale. (CP 6.10, EP1: 287)

51 Here, Peirce argues that not only are such appeals - at least in Galileo's case - an acceptable way of furthering scientific inquiry, but that they are actually necessary to do so. This becomes apparent in his 1898 "The First Rule of Logic," where Peirce argues that induction on the basis of facts can only take our reasoning so far:

The only end of science, as such, is to learn the lesson that the universe has to teach it. In Induction it simply surrenders itself to the force of facts. But it finds, at once [...] it finds I say that this is not enough. It is driven in desperation to call upon its inward sympathy with nature, its instinct for aid, just as we find Galileo at the dawn 
of modern science making his appeal to il lume naturale. But in so far as it does this, the solid ground of fact fails it. It feels from that moment that its position is only provisional. It must then find confirmations or else shift its footing. Even if it does find confirmations, they are only partial. It still is not standing upon the bedrock of fact. It is walking upon a bog, and can only say, this ground seems to hold for the present. Here I will stay till it begins to give way. (CP 5.589)

Peirce argues for the same idea in a short passage from 1896:

In examining the reasonings of those physicists who gave to modern science the initial propulsion which has insured its healthful life ever since, we are struck with the great, though not absolutely decisive, weight they allowed to instinctive judgments. Galileo appeals to il lume naturale at the most critical stages of his reasoning. Kepler, Gilbert, and Harvey - not to speak of Copernicus - substantially rely upon an inward power, not sufficient to reach the truth by itself, but yet supplying an essential factor to the influences carrying their minds to the truth.

It is certain that the only hope of retroductive reasoning ever reaching the truth is that there may be some natural tendency toward an agreement between the ideas which suggest themselves to the human mind and those which are concerned in the laws of nature. (CP 1.80)

In these passages, Peirce is arguing that in at least some cases, reasoning has to appeal at some point to something like il lume naturale in order for there to be scientific progress. In the above passage we see a potential reason why: one could reach any number of conclusions on the basis of a set of evidence through retroductive reasoning, so in order to decide which of these conclusions one ought to reach, one then needs to appeal to something beyond the evidence itself. Similarly, in the passage from "The First Rule of Logic," Peirce claims that inductive reasoning faces the same requirement: on the basis of a set of evidence there are many possible conclusions that one could reach as a result of induction, and so we need some other court of appeal for induction to work at all.

Note here that we have so far been discussing a role that Peirce saw il lume naturale playing for inquiry in the realm of science. Peirce does, however, make reference to $i$ lume naturale as it pertains to vital matters, as well. Consider, for example, the following passage from "Philosophy and the Conduct of Life" (1898):

Reasoning is of three kinds. The first is necessary, but it only professes to give us information concerning the matter of our own hypotheses and distinctly declares that, if we want to know anything else, we must go elsewhere. The second depends upon probabilities. The only cases in which it pretends to be of value is where we have, like an insurance company, an endless multitude of insignificant risks. Wherever a vital interest is at stake, it clearly says, "Don't ask me." The third kind of reasoning tries what il lume naturale, which lit the footsteps of Galileo, can do. It is really an appeal to instinct. Thus reason, for all the frills it customarily wears, in vital crises, comes down upon its marrow-bones to beg the succour of instinct. (RLT 111)

However, as we have already seen in the above passages, begging "the succour of instinct" is not a practice exclusive to reasoning about vital matters. At least at the time of "Philosophy and the Conduct of Life," though, Peirce is attempting to make a distinction between inquiry into scientific and vital matters by arguing that we have no choice but to rely on instinct in the case of the latter. But if induction and retroduction both require an appeal to il lume naturale, then why should Peirce think that there is really any important difference between the two areas of inquiry?

We think we can make sense of this puzzle by making a distinction that Peirce is himself not always careful in making, namely that between il lume naturale and instinct. As we 
have seen, Peirce is more often skeptical when it comes to appealing to instinct in inquiry, arguing that it is something that we ought to verify with experience, since it is something that we do not have any explicit reason to think will lead us to the truth. Peirce argues that il lume naturale, however, is more likely to lead us to the truth because those cognitions that come as the result of such seemingly natural light are both about the world and produced by the world. Consider how Peirce conceives of the role of il lume naturale as guiding Galileo in his development of the laws of dynamics, again from "The Architecture of Theories":

For instance, a body left to its own inertia moves in a straight line, and a straight line appears to us the simplest of curves. In itself, no curve is simpler than another [...] But the straight line appears to us simple, because, as Euclid says, it lies evenly between its extremities; that is, because viewed endwise it appears as a point. That is, again, because light moves in straight lines. Now, light moves in straight lines because of the part which the straight line plays in the laws of dynamics. Thus it is that, our minds having been formed under the influence of phenomena governed by the laws of mechanics, certain conceptions entering into those laws become implanted in our minds, so that we readily guess at what the laws are. Without such a natural prompting, having to search blindfold for a law which would suit the phenomena, our chance of finding it would be as one to infinity. The further physical studies depart from phenomena which have directly influenced the growth of the mind, the less we can expect to find the laws which govern them "simple," that is, composed of a few conceptions natural to our minds. (CP 6.10, emphasis ours)

Our minds, then, have been formed by natural processes, processes which themselves dictate the relevant laws that those like Euclid and Galileo were able to discern by appealing to the natural light. This means that il lume naturale does not constitute any kind of special faculty that is possessed only by great scientists like Galileo. Indeed, that those like Galileo were able to appeal to il lume naturale with such success pertained to the nature of the subject matter he studied: that the ways in which our minds were formed were dictated by the laws of mechanics gives us reason to think that our common sense beliefs regarding those laws are likely to be true.

In thinking about il lume naturale in this way, though, Peirce walks a thin line. While Galileo may have gotten things right, there is no guarantee that by appealing to my own natural light, or what I take to be the natural light, that I will similarly be led to true beliefs. Furthermore, justifying such beliefs by appealing to an apparent connection between the way that the world is and the way that my inner light guides me can lead us to lend credence to beliefs that perhaps do not deserve it. We can, however, now see the relationship between instinct and il lume naturale. As we have seen, instinct is not of much use when it comes to making novel arguments or advancing inquiry into complex scientific logic. ${ }^{12}$ We have also seen in our discussion of instinct that instincts are malleable and liable to change over time. When these instincts evolve in response to changes produced in us by nature, then, we are then dealing with il lume naturale.

So far we have unpacked four related concepts: common sense, intuition, instinct, and il lume naturale. We have seen that Peirce is not always consistent in his use of these concepts, nor is he always careful in distinguishing them from one another. That being said, now that we have untangled some of the most significant interpretive knots we can return to the puzzle with which we started and say something about the role that common sense plays in Peirce's philosophy. 


\section{Common Sense, Take 2: The Growth of Concrete Reasonableness}

60 As a practicing scientist and logician, it is unsurprising that Peirce has rigorous expectations for method in philosophy. Although many parts of his philosophical system remain in motion for decades, his commitment to inquiry as "laboratory philosophy" requiring the experimental mindset never wavers. Yet it is now quite clear that intuition, carefully disambiguated, plays important roles in the life of a cognitive agent. Instinct and il lume naturale as we have understood them emerging in Peirce's writings over time both play a role specifically in inquiry - the domain of reason - and in the exercise and systematization of common sense.

61 Our most basic instincts steer us smoothly when there are no doubts and there should be no doubts, thus saving us from ill-motivated inquiry. Our instincts that are specially tuned to reasoning - concerning association, giving life to ideas, and seeking the truth suggest that our lives are really doxastic lives. But that this is so does not mean, on Peirce's view, that we are constantly embroiled in theoretical enterprise. Quite the opposite:

For the most part, theories do little or nothing for everyday business. Nobody fit to be at large would recommend a carpenter who had to put up a pigsty or an ordinary cottage to make an engineer's statical diagram of the structure. In particular, applications of theories would be worse than useless where they would interfere with the operation of trained instincts. Who could play billiards by analytic mechanics? We all have a natural instinct for right reasoning, which, within the special business of each of us, has received a severe training by its conclusions being constantly brought into comparison with experiential results. Nay, we not only have a reasoning instinct, but [...] we have an instinctive theory of reasoning, which gets corrected in the course of our experience. So, it would be most unreasonable to demand that the study of logic should supply an artificial method of doing the thinking that his regular business requires every man daily to do. (CP 2.3)

Common sense systematized is a knowledge conservation mechanism: it tells us what we should not doubt, for some doubts are paper and not to be taken seriously. There are times, when the sceptic comes calling, to simply sit back and keep your powder dry.

This is perfectly consistent with the inquirer's status as a bog walker, where every step is provisional - for beliefs are not immune to revision on the basis of their common-sense designation, but rather on the basis of their performance in the wild. Even deeper, instincts are not immune to revision, but are similarly open to calibration and correction - to being refined or resisted. Just as we want our beliefs to stand up, but are open to the possibility that they may not, the same is true of the instincts that guide us in our practical lives - which are nonetheless the lives of generalizers, legislators, and would-be truth-seekers. In both belief and instinct, we seek to be concretely reasonable. Thus, the epistemic stance that Peirce commends us to is a mixture: a blend of what is new in our natures, the remarkable intelligence of human beings, and of what is old, the instincts that tell their own story of our evolution toward rationality. For instance, what Peirce calls the "abductive instinct" is the source of creativity in science, of the generation of hypotheses. What he recommends to us is also a blended stance, an epistemic attitude holding together conservatism and fallibilism. 

that we can better appreciate why he is with it "in the main." Common sense calls us to an epistemic attitude balancing conservatism and fallbilism, which is best for balancing our theoretical pursuits and our workaday affairs. The process of unpacking much of what Peirce had to say on the related notions of first cognition, instinct, and il lume naturale motivate us to close by extending this attitude in a metaphilosophical way, and into the 21st century. We now turn to intuitions and common sense in contemporary metaphilosophy, where we suggest that a Peircean intervention could prove illuminating.

\section{The Take-Home: Grounded Intuitions}

Peirce's discussions of common sense and the related concepts of intuition and instinct are not of solely historical interest, especially given the recent resurgence in the interest of the role of the intuitive in philosophy. These are currently two main questions addressed in contemporary metaphilosophical debates: a descriptive question, which asks whether intuitions do, in fact, play a role in philosophical inquiry, and a normative question, which asks what role intuitions ought to play a role in such inquiry. As we will see, the contemporary metaphilosophical questions are of a kind with the questions that Peirce was concerned with in terms of the role of common sense and the intuitive in inquiry generally; both ask when, if at all, we should trust the intuitive. In this final section we will consider some of the main answers to these questions, and argue that Peirce's views can contribute to the relevant debates.

That philosophers will at least sometimes appeal to intuitions in their arguments seems close to a truism. However, there have recently been a number of arguments that, despite appearances, philosophers do not actually rely on intuitions in philosophical inquiry at all. Herman Cappellen (2012) is perhaps the most prominent proponent of such a view: he argues that while philosophers will often write as if they are appealing to intuitions in support of their arguments, such appeals are merely linguistic hedges. Most other treatments of the question do not ask whether philosophers appeal to intuitions at all, but whether philosophers treat intuitions as evidence for or against a particular theory. Max Deutsch (2015), for example, answers this latter question in the negative, arguing that philosophers do not rely on intuitions as evidential support; Jonathan Ichikawa (2014) similarly argues that while intuitions play some role in philosophical inquiry, it is the propositions that are intuited that are treated as evidence, and not the intuitions themselves. On the other side of the debate there have been a number of responses targeting the kinds of negative descriptive arguments made by the above and other authors. Nevin Climenhaga (forthcoming), for example, defends the view that philosophers treat intuitions as evidence, citing the facts that philosophers tend to believe what they find intuitive, that they offer error-theories in attempts to explain away intuitions that conflict with their arguments, and that philosophers tend to increase their confidence in their views depending on the range of intuitions that support them. Richard Boyd (1988) has suggested that intuitions may be a species of trained judgment whose nature is between perceptual judgment and deliberate inference.

How might Peirce weigh in on the descriptive question? As we have seen, the answer to this question is not straightforward, given the various ways in which Peirce treated the notion of the intuitive. In the sense of "intuition" used as "first cognition" Peirce is adamant that no such thing exists, and thus in this sense Peirce would no doubt answer

European Journal of Pragmatism and American Philosophy, IX-2 | 2017 
the descriptive question in the negative. We have also seen that what qualifies as the intuitive for Peirce is much more wide-ranging. If we take what contemporary philosophers thinks of as intuition to also include instinct, il lume naturale, and common sense, then Peirce holds the mainstream metaphilosophical view that intuitions do play a role in inquiry.

If philosophers do, in fact, rely on intuitions in philosophical inquiry, ought they to do so? We have seen that this normative problem is one that was frequently on Peirce's mind, as is exemplified in his apparent ambivalence over the use of the intuitive in inquiry. Recently, there have been many worries raised with regards to philosophers' reliance on intuitions. Carrie Jenkins (2014) summarizes some of the key problems as follows:

(1) The nature, workings, target(s) and/or source(s) of intuitions are unclear.

(2) Why should we think intuitions are reliable, epistemically trustworthy, a source of evidence, etc.?

(3) Intuitions exhibit cultural variation/intra-personal instability/inter-personal clashes.

(4) There is no way to calibrate intuitions against anything else.

(5) It is not naturalistically respectable to give epistemic weight to intuitions.

Peirce raises a number of these concerns explicitly in his writings. He raises issues similar to (1) throughout his "Questions Concerning Certain Faculties," where he argues that we are unable to distinguish what we take to be intuitive from what we take to be the result of processes of reasoning. As Peirce thinks that we are, at least sometimes, unable to correctly identify our intuitions, it will be difficult to identify their nature. We have seen that he has question (2) in mind throughout his writing on the intuitive, and how his ambivalence on the right way to answer it created a number of interpretive puzzles. In general, though, the view that the intuitive needs to be somehow verified by the empirical is a refrain that shows up in many places throughout Peirce's work, and thus we get the view that much of the intuitive, if it is to be trusted at all, is only trustworthy insofar as it is confirmed by experience. Peirce raises worry (3) most explicitly in his "Fixation of Belief" when he challenges the method of the a priori: that reasoning according to such a method is not a good method for fixing beliefs is because such reasoning relies on what one finds intuitive, which is in turn influenced by what one has been taught or what is popular to think at the time.

It is less clear whether Peirce thinks that the intuitive can be calibrated. The metaphilosophical worry here is that while we recognize that our intuitions sometimes lead us to the truth and sometimes lead us astray, there is no obvious way in which we can attempt to hone our intuitions so that they do more of the former than the latter. That our instincts evolve and change over time implies that the intuitive, for Peirce, is capable of improving, and so it might, so to speak, self-calibrate insofar as false intuitive judgements will get weeded out over time. When it comes to individual inquiries, however, it's not clear whether our intuitions can actually be improved, instead of merely checked up on. ${ }^{13}$ While Peirce seemed skeptical of the possibility of calibrating the intuitive when it came to matters such as "scientific logic," there nevertheless did seem to be some other matters about which our intuitions come pre-calibrated, namely those produced in us by nature. Because such intuitions are provided to us by nature, and because that class of the intuitive has shown to lead us to the truth when applied in the right domains of inquiry, Peirce will disagree with (5): it is, at least sometimes, naturalistically appropriate to give epistemic weight to intuitions. 
71 How, then, might Peirce answer the normative question generally? To get an idea it is perhaps most illustrative to look back at Peirce's discussion of il lume naturale. As we saw above, il lume naturale is a source of truths because we have reason to believe that it produces intuitive beliefs about the world in the right way: as beings of the world ourselves, we are caused to believe facts about the world in virtue of the way that the world actually is. The natural light, then, is one that is provided by nature, and is reflective of nature. Call intuitive beliefs that result from this kind of process grounded: their content is about facts of the world, and they come about as a result of the way in which the world actually is. ${ }^{14}$ Il lume naturale represents one source of grounded intuitions for Peirce. But we can also see that instincts and common sense can be grounded for Peirce, as well.

Consider, for example, how Peirce discusses the conditions under which it is appropriate to rely on instinct: in his "Ten Pre-Logical Opinions," the fifth is that we have the opinion that reason is superior to instinct and intuition. Peirce argues that this clearly is not always the case: there are times at which we rely on our instincts and they seem to lead us to the truth, and times at which our reasoning actually gets in our way, such that we are lead away from what our instinct was telling us was right the whole time. There are of course other times at which our instincts and intuitions can lead us very much astray, and in which we need to rely on reasoning to get back on track. Peirce seems to think that the cases in which we should rely on our instincts are those instances of decision making that have to do with the everyday banalities of life. On the other hand,

When one's purpose lies in the line of novelty, invention, generalization, theory - in

a word, improvement of the situation - by the side of which happiness appears a

shabby old dud - instinct and the rule of thumb manifestly cease to be applicable.

(CP 2.178)

Peirce is fond of comparing the instincts that people have to those possessed by other animals: bees, for example, rely on instinct to great success, so why not think that people could do the same? That the instinct of bees should lead them to success is no doubt the product of their nature: evolution has guided their development in such a way to be responsive to their environment in a way that allows them to thrive. Of course, bees are not trying to develop complex theories about the nature of the world, nor are they engaged in any reasoning about scientific logic, and are presumably devoid of intellectual curiosity. We have seen that when it comes to novel arguments, complex mathematics, etc., Peirce argues that instinct is not well-suited to such pursuits precisely because we lack the "full stock of instincts" that one would need to employ in new situations and when thinking about new problems. This is not to say that we lack any kind of instinct or intuition when it comes to these matters; it is, however, in these more complex matters where instinct and intuition lead us astray - in which they fail to be grounded - and in which reasoning must take over.

Peirce is not alone in his view that we have some intuitive beliefs that are grounded, and thereby trustworthy. Consider, for, example, a view from Ernst Mach:

Everything which we observe imprints itself uncomprehended and unanalyzed in our percepts and ideas, which then, in their turn, mimic the process of nature in their most general and most striking features. In these accumulated experiences we possess a treasure-store which is ever close at hand, and of which only the smallest portion is embodied in clear articulate thought. The circumstance that it is far easier to resort to these experiences than it is to nature herself, and that they are, 
notwithstanding this, free, in the sense indicated, from all subjectivity, invests them with high value. (Mach 1960 [1883]: 36)

It is not clear that Peirce would agree with Mach that such ideas are free from "all subjectivity"; nevertheless, the kinds of ideas that Mach discusses are similar to those which Peirce discusses as examples of being grounded: the source of that which is intuitive and grounded is the way the world is, and thus is trustworthy. Jenkins (2008) presents a much more recent version of a similar view. She considers why intuition might be trustworthy when it comes specifically to mathematical reasoning:

Our concepts are representations of the world; as such, they can serve as a kind of map of that world. Examining this conceptual map can - and probably often does amount to thinking about the world and not about these representations of it. In doing conceptual examination we are allowing our concepts to guide us, but we need not be aware that they are what is guiding us in order to count as performing an examination of them in my intended sense [...] By way of filling in the rest of the story, I want to suggest that, if our concepts are somehow sensitive to the way the independent world is, so that they successfully and accurately represent that world, then an examination of them may not merely be an examination of ourselves, but may rather amount to an examination of an accurate, on-board conceptual map of the independent world. And I want to suggest that we might well be able to acquire knowledge about the independent world by examining such a map. (Jenkins 2008: 124-6)

76 Jenkins suggests that our intuitions can be a source of truths about the world because they are related to the world in the same way in which a map is related to part of the world that it is meant to represent. Importantly for Jenkins, reading a map does not tell us something just about the map itself: in her example, looking at a map of England can tell us both what the map represents as being the distance from one city to another, as well as how far the two cities are actually apart. Intuitions are psychological entities, but by appealing to grounded intuitions, we do not merely appeal to some facts about our psychology, but to facts about the actual world.

Thus, on our reading, Peirce maintains that there is some class of the intuitive that can, in fact, lead us to the truth, namely those grounded intuitions. Do grounded intuitions thus exhibit a kind of epistemic priority as defended by Reid, such that they have positive epistemic status in virtue of being grounded? Peirce's comments on il lume naturale and instincts provided by nature do indeed sound similar to Reid's view that common sense judgments are justified prior to scrutiny because they are the product of reliable sources. However, that grounded intuitions for Peirce are truth-conducive does not entail that they have any kind of epistemic priority in Reid's sense. Again, since we are unable to tell just by introspection whether our judgments are the products of instinct, intuition, or reasoning, and since the dictates of common sense and its related concepts are malleable and evolve over time, Peirce cannot take an intuitive judgment to be, by itself, justified. Instead, grounded intuitions are the class of the intuitive that will survive the scrutiny generated by genuine doubt.

However, that there is a category of the intuitive that is plausibly trustworthy does not solve all of the problems that we faced when considering the role of intuitions in philosophical discourse. Consider, for example, two maps that disagree about the distance between two cities. On the basis of the maps alone there is no way to tell which one is actually correct; nor is there any way to become better at identifying correct maps in the future, provided we figure out which one is actually right in this particular instance. General worries about calibration will therefore persist. There is, however, another 
response to the normative problem that Peirce can provide - one that we think is unique, given Peirce's view of the nature of inquiry.

The contemporary normative question is really two questions: "ought the fact that something is intuitive be considered evidence that a given view is true or false?" and "is the content of our intuitions likely to be true?" In contemporary debates these two questions are treated as one: if intuitions are not generally truth-conducive it does not seem like we ought to treat them as evidence, and if we ought to treat them as evidence then it seems that we ought to do so just because they are truth-conducive. But these questions can come apart for Peirce, given his views of the nature of inquiry. This is because for Peirce inquiry is a process of fixing beliefs to resolve doubt. What creates doubt, though, does not need to have a rational basis, nor generally be truth-conducive in order for it to motivate inquiry: as long as the doubt is genuine, it is something that we ought to try to resolve.

One potential source of doubt is our intuitions themselves: that a given theory has counterintuitive consequences is taken to be a reason to question that theory, as well as motivating us to either find a new theory without such consequences, or else to provide an error theory to explain why we might have the intuitions that we do without giving up the theory. But intuitions can play a dialectical role without thereby playing a corresponding evidential role: that we doubt whether $p$ is true is not necessarily evidence that $p$ is not true. That something can motivate our inquiry into $p$ without being evidence for or against that $p$ is a product of Peirce's view of inquiry according to which genuine doubt, regardless of its source, ought to be taken seriously in inquiry. We have, then, a second answer to the normative question: we ought to take the intuitive seriously when it is a source of genuine doubt. While the contemporary debate is concerned primarily with whether we ought epistemically to rely on intuitions in philosophical inquiry, according to Peirce there is a separate sense in which their capacity to generate doubt means that we ought methodologically to be motivated by intuitions.

\section{Conclusion}

We started with a puzzle: Peirce both states his allegiance to the person who contents themselves with common sense and insists that common sense ought not have any role to play in many areas of inquiry. We have seen that this ambivalence arises numerous times, in various forms: Peirce calls himself a critical common-sensist, but does not ascribe to common sense the epistemic or methodological priority that Reid does; we can rely on common sense when it comes to everyday matters, but not when doing complicated science, except when it helps us with induction or retroduction; uncritical instincts and intuitions lead us to the truth just as often as reasoning does, but there are no cognitions that have positive epistemic status without having survived scrutiny; and so forth. Indeed, this ambivalence is reflective of a fundamental tension in Peirce's epistemology, one that exists between the need to be a fallibilist and anti-skeptic simultaneously: we need something like common sense, the intuitive, or the instinctual to help us get inquiry going in the first place, all while recognizing that any or all of our assumptions could be shown to be false at a moment's notice. We have shown that this problem has a contemporary analogue in the form of the metaphilosophical debate concerning reliance on intuitions: how can we reconcile the need to rely on the intuitive while at the same time realizing that our intuitions are highly fallible? 
While we are necessarily bog-walkers according to Peirce, it is not as though we navigate the bog blindly. Experience is no doubt our primary guide, but common sense, intuition, and instinct also play a role, especially when it comes to mundane, uncreative matters. We have argued that Peirce held that the class of the intuitive that is likely to lead us to the truth is that which is grounded, namely those cognitions that are about and produced by the world, those cognitions given to us by nature.

What we can extract from this investigation is a way of understanding the Peircean pragmatist's distinctive take on our epistemic position, which is both fallibilist as inquirer and commonsensically anti-sceptical. In light of the important distinction implicit in Peirce's writings between intuition, instinct, and il lume naturale, here developed and made explicit, we conclude that a philosopher with the laboratory mindset can endorse common sense and ground her intuitions responsibly.

\section{BIBLIOGRAPHY}

ATKINS Richard K., (2016), Peirce and the Conduct of Life: Sentiment and Instinct in Ethics and Religion, Cambridge, Cambridge University Press.

BERGMAN Mats, (2010), "Serving Two Masters: Peirce on Pure Science, Useless Things, and Practical Applications," in Mats Bergman, Sami Paavola, Ahti Veikko Pietarinen \& Henrik Rydenfelt (eds.), Ideas in Action: Proceedings of the Applying Peirce Conference, Nordic Studies in Pragmatism 1, Helsinki, Nordic Pragmatism Network, 17-37.

BOYD Kenneth, (2012), “Levi's Challenge and Peirce's Theory/Practice Distinction," Transactions of the Charles S. Peirce Society, 48.1, 51-70.

BOYD Kenneth \& Diana HENEY, (2017), "Rascals, Triflers, and Pragmatists: Developing a Peircean Account of Assertion," British Journal for the History of Philosophy, 25.2, 1-22.

BOYD Richard, (1988), "How to be a Moral Realist," in Geoffrey Sayre-McCord (ed.), Essays on Moral Realism, Ithaca, Cornell University Press, 181-228.

CAPPELEN Herman, (2012), Philosophy Without Intuitions, Oxford, Oxford University Press.

CLIMENHAGa Nevin, (forthcoming), "Intuitions are used as evidence in philosophy," Mind.

DE WAAL Cornelius (2012), “'Who's Afraid of Charles Sanders Peirce?' Knocking Some Critical Common Sense ino Moral Philosophy," in Cornelius de Waal \& Krzysztof Piotr Skowronski (eds.), The Normative Thought of Charles S. Peirce, New York, Fordham University Press.

DEUTSCH Max, (2015), The Myth of the Intuitive, Cambridge, MIT Press.

GRECO John, (2011), “Common Sense in Thomas Reid," Canadian Journal of Philosophy, 41.1, 142-55.

HENEY Diana B., (2014), "Peirce on Science, Practice, and the Permissibility of 'Stout Belief'," in Torkild Thellefsen \& Bent Sørensen (eds.), Charles S. Peirce in His Own Words - The Peirce Quote Volume, Mouton de Gruyter. 
ICHIKAWA Jonathan, (2014), "Who Needs Intuitions? Two Experimentalist Critiques," in Booth Anthony Robert \& Darrell P. Rowbottom (eds.), Intuitions, Oxford, Oxford University Press, 232-55. JENKINS Carrie, (2008), Grounding Concepts, Oxford, Oxford University Press.

JENKINS Carrie, (2014), “Intuition, 'Intuition,' Concepts and the A Priori,” in Booth Anthony Robert \& Darrell P. Rowbottom (eds.), Intuitions, Oxford, Oxford University Press, 91-115.

LOCKE John, (1975 [1689]), An Essay Concerning Human Understanding, edited and with an Introduction by Peter H. Nidditch, Oxford, Oxford University Press.

MACH Ernst, (1960 [1883]), The Science of Mechanics, LaSalle, IL, Open Court Publishing.

MASSECAR Aaron, (2016), Ethical Habits: A Peircean Perspective, Lexington Books.

MigotTI Mark, (2005), “The Key to Peirce’s View of the Role of Belief in Scientific Inquiry,” Cognitio , 6/1, 44-55.

NUBIOLA Jaime, (2004), "Il Lume Naturale: Abduction and God," Semiotiche, 1/2, 91-102. E-print: [ unav.es/users/LumeNaturale.html].

PEIRCE Charles Sanders, The Charles S. Peirce Manuscripts, Cambridge, MA, Houghton Library at Harvard University. Citations are by manuscript number, per the Robin catalogue $(1967,1971)$. PEIRCE Charles Sanders, (1900 - ), The Writings of Charles S. Peirce: A Chronological Edition, E. Moore (ed.), Bloomington, Indiana University Press. Cited as W plus volume and page number.

PEIRCE Charles Sanders, (1931-58), Collected Papers of Charles Sanders Peirce, I-VI C. Hartshorne \& P. Weiss (eds.); VII and VIII, A. Burks (ed.), Cambridge, MA, Belknap Press. Cited as CP plus volume and paragraph number.

PEIRCE Charles Sanders, (1992), Reasoning and the Logic of Things: The Cambridge Conferences Lectures of 1898, Kenneth Ketner and Hilary Putnam (eds.), Harvard University Press. Cited as RLT plus page number.

PEIRCE Charles Sanders, (1992-8), The Essential Peirce, 2 vols., Nathan Houser and Christian Kloesel \& the Peirce Edition Project (eds.), Bloomington, Indiana University Press.

PEIRCE Charles Sanders, (1997), Pragmatism as a Principle and Method of Right Thinking, Patricia Ann Turrisi (ed.), Albany, State University of New York Press. Cited as PPM plus page number.

REID Thomas, (1983), Thomas Reid, Philosophical Works, by H. M. Bracken (ed.), Hildesheim, Georg Olms.

ROBIN Richard, (1967), Annotated Catalogue of the Papers of Charles S. Peirce, Amherst, The University of Massachusetts Press.

ROBIN Richard, (1971), “The Peirce Papers: A Supplementary Catalogue," Transactions of the Charles S. Peirce Society, 7/1, 37-57.

\section{NOTES}

1. Peirce also occasionally discusses Dugald Steward and William Hamilton, but Reid is his main stalking horse.

2. As we shall see, Peirce's discussion of this difficulty puts his views in direct contact with contemporary metaphilosophical debates concerning intuition. We return to this point of contact in our "Take Home" section. 
3. See, for example, Atkins 2016, Bergman 2010, Migotti 2005.

4. Although Peirce was once again in very dire straits, as he had been in 1898 , the subject matter of the later lectures cannot be interpreted as a bad-tempered response to James - though they do offer a number of disambiguations between James' pragmatism and Peirce's pragmaticism. Heney 2014 has argued, following Turrisi 1997 (ed. Peirce), that the Harvard lectures are a critical text for the history of American philosophy.

5. Regarding James' best-known account of what is permissible in the way of belief formation, Peirce wrote the following directly to James: "I thought your Will to Believe was a very exaggerated utterance, such as injures a serious man very much" (CWJ 12: 171; 1909). A key part of James' position is that doxastically efficacious beliefs are permissible when one finds oneself in a situation where a decision about what to believe is, among other things, forced.

6. That definition can only be nominal, because the definition alone doesn't capture all that there is to say about what allows us to isolate intuition according to a pragmatic grade of clarity. There are many uncritical processes which we wouldn't call intuitive (or good, for that matter).

7. This does not mean that it is impossible to discern - Atkins makes this argument in response to de Waal (see Atkins 2016: 49-55).

8. Some of the relevant materials here are found only in the manuscripts, and for these Atkins 2016 is a very valuable guide.

9. See de Waal 2012.

10. In our view: for worse. We merely state our stance without argument here, though we say something of these and related matters in Boyd 2012, Boyd \& Heney 2017.

11. As Jaime Nubiola (2004) notes, the editors of the Collected Papers attribute the phrase "il lume naturale" to Galileo himself, which would explain why Peirce's discussions of il lume naturale so often accompany discussions of Galileo. As Nubiola also notes, however, the phrase does not appear to be one that Galileo used with any significant frequency, nor in quite the same way that Peirce uses it.

12. The exception, depending on how one thinks about the advance of inquiry, is the use of instinct in generating hypotheses for abductive reasoning (see CP 5.171).

13. Recall that the process of training one's instincts up in a more reasonable direction can be sparked by a difficulty posed mid-inquiry, but such realignment is not something we should expect to accomplish swiftly. For a discussion of habituation in Peirce's philosophy, see Massecar 2016.

14. A very stable feature of Peirce's view as they unfold over time is that our experience of reality includes what he calls Secondness: "insistence upon being in some quite arbitrary way is Secondness, which is the characteristic of the actually existing thing" (CP 7.488). Perhaps attuned to the critic who will cry out that this is too metaphysical, Peirce gives his classic example of an idealist being punched in the face. "[A]n idealist of that stamp is lounging down Regent Street, thinking of the utter nonsense of the opinion of Reid, and especially of the foolish probatio ambulandi, when some drunken fellow who is staggering up the street unexpectedly lets fly his fist and knocks him in the eye. What has become of his philosophical reflections now?" (CP 5.539). Peirce suggests that the idealist will come to appreciate the "objectivity" of the unexpected, and rethink his stance on Reid. 


\section{ABSTRACTS}

In addition to being a founder of American pragmatism, Charles Sanders Peirce was a scientist and an empiricist. A core aspect of his thoroughgoing empiricism was a mindset that treats all attitudes as revisable. His fallibilism seems to require us to constantly seek out new information, and to not be content holding any beliefs uncritically. At the same time, Peirce often states that common sense has an important role to play in both scientific and vital inquiry, and that there cannot be any "direct profit in going behind common sense." Our question is the following: alongside a scientific mindset and a commitment to the method of inquiry, where does common sense fit in? Peirce does at times directly address common sense; however, those explicit engagements are relatively infrequent. In this paper, we argue that getting a firm grip on the role of common sense in Peirce's philosophy requires a three-pronged investigation, targeting his treatment of common sense alongside his more numerous remarks on intuition and instinct. By excavating and developing Peirce's concepts of instinct and intuition, we show that his respect for common sense coheres with his insistence on the methodological superiority of inquiry. We conclude that Peirce shows us the way to a distinctive epistemic position balancing fallibilism and anti-scepticism, a pragmatist common sense position of considerable interest for contemporary epistemology given current interest in the relation of intuition and reason.

\section{AUTHORS}

\section{KENNETH BOYD}

University of Toronto, Scarborough

kenneth.boyd[at]gmail.com

\section{DIANA HENEY}

Fordham University

dheney[at]fordham.edu 